\section{MANITOBA WHOOPERS - 40 YEARS AGO}

HAROLD E. WATSON, 220 Franklin Street, Brandon, Manitoba. R7A 5P3

The following note is excerpted from a letter written 28 March 1974 to the editors of Wild Wings and Chickadee Notes. The belated report was made then due to recent (at that time) reports of Whooping Cranes "in the Winnipeg area, and out towards Rock Lake" being "almost totally discounted. .. "'

The sighting I had belatedly written about, "occurred about the 10th of May, in either 1944, or 45, and was while 7 or 8 of us CPR Employees were eating lunch outside the Shops [in Brandon, Manitoba].

We had just started eating our lunches when I heard an unusual crane-like cry and upon looking up, I was amazed to see 5 large glistening white birds, with outstretched wings soaring in small circles at a very great height.

The other fellows soon looked to where I pointed and saw them too, and as we ate, they circled and called, no doubt excited by the sight of the Assiniboine below. We could see that they were high, because a plane from \#2 Flying Field flew below them and was only about half the height of the birds.

We, in spite of the height, could see the black tips on their wings and their legs trailing, necks outstrectched and long beaks.

They circled off on a course that would be about north-east by north, and we could hear them until they were almost out of sight. . . ...

I am sure that all of the group who saw them, will never forget seeing them, as they sure were large; and sure were white, except for wing tips and legs, and they sure could make themselves heard.

Bill [W.H. Armstrong] and I, and no doubt the others [lack Irving, Scottie Manson, Torchy Crawford, Bill Vellam and Herman Phelps, since deceased] too, realised how fortunate we were to see them, for about those years their numbers were down to about 17 , so we almost saw one third of all there were.

In a recent telephone conversation with Bill, he stated that the sighting was made in 1944. . . .

Since writing that previous letter, I heard from a now deceased Cousin that her Uncle, the late Dr. Robert Goodwin had not only seen them, but had shot them. Dr Goodwin, a Brother of my Great Uncle Alex, ..... . like his brothers was also a noted hunter having been hunting at an early age in I believe, the Amprios area northwest of Ottawa." .... .

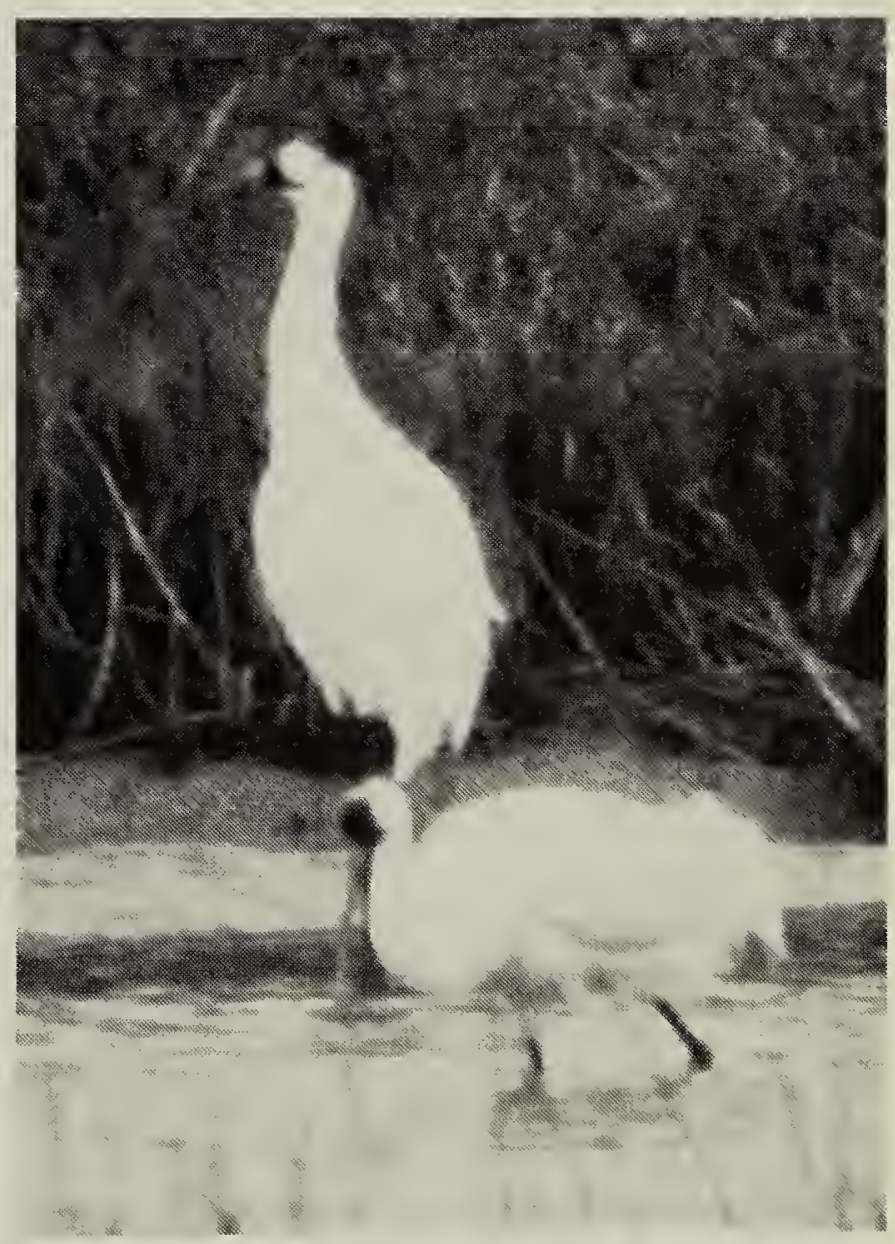

Whooping Cranes at Aransas N.W.R.

J. Sutherland 